\title{
Conferência
}




\section{REFLEXÕES PARA O ESTABELECIMENTO DE UMA POLITIICA PARA AS HUMANIDADES}

$\mathbb{N} \begin{aligned} & \text { ão tenho evidentemente a pretensão de, nesta conferência, } \\ & \text { estabelecer uma política para as I lumanidades. Isso não será }\end{aligned}$ o trabalho de uma só pessoa, pois, como sabemos todos os que trabalhamos com o discurso científico, este não atua como o discurso religioso, que apresenta uma explicação total e definitiva para o mundo, mas, ao contrário, faz aproximações sucessivas do objeto. Diferentemente do discurso religioso, que não precisa da comprovação dos fatos, o discurso científico precisa do teste da realidade e, por isso, é da sua natureza a publicidade dos resultados, o debate, a crítica e a contradição, para que esse conhecimento vá aproximando-se da verdade. Por acreditar profundamente nisso, apresentarei alguns pontos de vista acerca da questão, para que possam ser discutidos, questionados, a fim de que certos consensos provisórios (pois é sempre provisório e parcial o consenso científico) possam formar-se na comunidade de pesquisadores em L Letras e Lingüística.

Pensar uma política para as I lumanidades implica refletir sobre:

1. o papel da Universidade em geral e das I lumanidades em particular na socicdade contemporânea;

2. o estado da arte da área, com suas crises, seus impasses, a mudança de paradigmas teóricos;

3. os problemas relativos à formação de novos pesquisadores.

Comecemos por lembrar-nos de uma cena do filme de Spielberg, A lista de Schindler. Um judeu podia salvar-se da morte no campo de concentração, se fosse considerado um trabalhador essencial ao esforço de guerra

* Universidade de São Paulo - USP. 
FIORIN, José I uiz. Reflexões para o estabelecimento de uma política para as Itumanidades.

nazista, ou seja, se fosse incluído na lista de Schindler: Uma personagem aproxima-se da mesa de inscrição e diz com orgulho: "Sou um trabalhador essencial". O soldado nazista pergunta-lhe: "Qual é sua profissão?". Ela responde: "Professor de literatura e história". O soldado começa a rir; indicando-lhe o lugar dos excluídos, dos inessenciais. Perplexa, a personagem indaga: "Mas o que pode ser mais essencial do que a história e a literatura?" Comentando essa cena, diz Marilena Chaú:

Esta cena parece-me antológica por vários motivos. Em primeiro lugar; evidentemente, por sua dimensão patética: o professor de história e de literatura não percebeu o que se passa à sua volta. Em segundo lugar, por seu caráter simbólico: o professor não compreendeu que um mundo no qual história e liceratura são essenciais é um mundo terminado com o advento da barbárie nazista. Em terceiro lugar, por sua natureza quase oracular: terminavam ali o ideal e a ilusão de uma razão não instrumental $(1996,161)$.

O mundo nazista é um mundo da ação pela ação, base ideológica de todos os fascismos. Nele não tem nenhuma importância o sentido da ação. Atualmente, as letras maiúsculas que ornavam palavras como I listória, Humanidades, Direitos Humanos, Justiça, Igualdade, Liberdade, Solidariedade, Internacionalismo, Proletariado parece terem desaparecido. Só os sem terra e outros desterrados e esquecidos parece lembraremnos dessas maiúsculas.

A Universidade surgiu com uma vocação universalista. É o que diz a etimologia da palavra. Durante séculos, ela foi uma instituição de um mundo caracterizado pela totalidade da experiência cultural. No entanto, hoje ela está no interior de um mundo marcado pela fragmentação dessa experiência. O alto grau de especialização, o volume do conhecimento produzido em cada uma dessas especializações e a diversificação do conhecimento tornaram os diferentes domínios científicos separados, de forma que, em geral, não se tem uma visão global do domínio cultural. Até no âmbito de uma mesma disciplina, não se tem mais uma visão global do desenvolvimento das várias subáreas e dos diferentes objetos teóricos. 
Se não se consegue uma visão global dentro de uma mesma disciplina, como se pode pretender uma visão crítica da epistemé comum aos vários campos (Silva, 1996, 105-110)?

Por outro lado, estamos assistindo a um processo chamado globalização do mundo. Determinado pelas novas formas de produção, corresponde cle a um processo que se caracteriza por uma integração econômica, política e cultural de países, por uma certa "queda" de fronteiras. Isso quer dizer que não só a circulação de mercadorias e de capitais não obedece à lógica das fronteiras nacionais, mas também que começam a aparecer bens culturais que não estão circunscritos à lógica das identidades nacionais, mas recortam os grupos nacionais transversalmente, fazendo que determinados setores da população consumam os mesmos produtos culturais, tenham os mesmos gostos, os mesmos valores, em Nova Iorque, Paris, Rio de Janeiro ou São Paulo. José Saramago, em conferência na Universidade de São Paulo, disse, numa síntese lapidar, como os grandes escritores sabem fazer, que a União Européia estava criando uma nova Iugoslávia na Europa. Com efeito, a frase de Saramago indica algo paradoxal ou aparentemente paradoxal. A esse movimento de globalização cconômica, política e cultural corresponde um movimento, de igual força, que vai em sentido inverso, o surgimento das reivindicações da aceitação de particularismos culturais e étnicos, o que implica o surgimento dos novos nacionalismos, dos separatismos, da xenofobia, do fundamentalismo, do reconhecimento da singularidade das minorias. Ao mesmo tempo em que se vão esmaecendo as referências nacionais, adquire extrema importância a questão das identidades regionais e locais, de que o ressurgir dos dialetos constitui um exemplo marcante. A fragmentação da cultura contemporânea consiste em "separar elementos e depois juntá-los em regime de exterioridade recíproca” (Silva, 1996, 109), o que significa que não há articulação dos diferentes campos, das diversas identidades, etc. Ora, isso significa a destruição da diversidade. Pensemos um pouco mais essa questão. O latim possuía dois termos para significar "todo": omnis e totus. A oposição entre os dois se faz pelos traços /integralidade/ $\mathrm{c} /$ universalidade/. 
FIORIN, José I uiz. Reflexões para o estabelecimento de uma polílica para as I lumanidades.

Com efeito, totus indica uma grandeza discreta, ou seja, distinta daquilo que ela não é (unus), e uma grandeza compreendida globalmente em sua integralidade, sublinhando a absorção das partes numa massa indivisível, concebida como um bloco em que as partes são dominadas pelo todo. Já omnis denota uma coleção, isto é, "uma reunião de indivíduos num gTupo, cujas partes componentes são reconhecidas como reais e, ao mesmo tempo, partes de um conjunto" (Brøndal, 1986, 15). Isso significa que a diversidade caracteriza o totus, pois ganha ela sentido pela articulação com uma totalidade. Já a característica do omnis é a fragmentação das partes que a compõem. Ora, a cultura contemporânea nega um processo de totalização e constrói, se me permitem o bárbaro neologismo, um processo de omnização, de universalização.

Ademais, na sociedade de massas, que seria preciso analisar mais detidamente, os bens culturais tendem a tornar-se objetos de consumo. Ora, cultura significa etimologicamente cultivo e preservação (Silva, 1996, 116). Isso quer dizer que ela implica uma duratividade, enquanto o consumo implica pontualidade. Enquanto a cultura não é descartável, o objeto de consumo o é.

O cultural não é o efêmero, embora o efêmero possa dar origem ao cultural: as realizações do espírito prevalecem sobre as vicissitudes históricas, a menos que o devir histórico se confunda com o advento da barbárie. Elas são superadás pelo progresso do conhecimento, embora se relacionem, no seu processo de aparecimento, com o estágio de conhecimento em cada época. $\Lambda$ universalidade é histórica, mas não é completamente sujeita às conjunturas históricas (Silva, 1996, 116).

Tùdo isso, globalização econômica, política e cultural, fragmentação cultural, transformação de bens culturais em objetos de consumo são efeitos do que os "neobobos", os "toscos", os "atrasados" chamariam "acumulação flexível do capital" e os "modernos" denominariam "desregulação econômica", que é a forma de acumulação a que chegou o capitalismo cm nossa época. Essa acumulação flexível do capital exige que todos os serviços que antes pertenciam à esfera do Estado e, por conseguinte, eram 
vistos como domínios alheios à lógica do mercado passem a ser guiados por cla (Cf. Chaú, 1996, 165-168).

Nesse mundo, qual é o papel e o sentido da Universidade? Qual é nele o papel das Ilumanidades?

Aparece aqui um primeiro mal-estar: manter uma universidade da qual está ausente a universalidade. "O que significa para a universidade ser ou existir num contexto cultural marcado pela fragmentação e pelo consumo, pelo imediatismo tecnicista e pela alienação objetivista, eis a verdadeira questão, aquele a que nunca se dará solução, pois o problema, posto nestes termos, não é daqueles que admitem resposta. A única resposta à situação universitária contemporânea só pode consistir na clara elaboração da 'questão da universidade', na manutenção e constante alimentação desta interrogação, procedimento pelo qual se pensará a universidade no plano do sujeito histórico e não apenas no plano das conseqüências das determinações culturais da modernidade" (Silva, 1996, 117). Um projeto de universidade hoje "deve brotar do confronto entre as aspirações de resgate cultural e o devir histórico da contemporancidade" (Silva, 1996, 117).

Pensemos agora nas Humanidades dentro desse contexto. Ou melhor, particularizemos um pouco mais: qual é o papel das Letras e da Lingüística dentro desse panorama? Diante da crise da universidade, pensase em salvá-la, modernizando-a. Que significa exatamente a modernização universitária? Segundo Marilena Chauí, "modernizar" é criar a "universidade de serviços", fundada na docência e na pesquisa de "resultados", ou seja, é transformar o critério de excelência da universidade no teste do mercado. "Quem conseguir penetrar vitoriosamente no mercado será excelente; quem não o conseguir, será inessencial. Critério coerente e não absurdo, uma vez que a fonte de recursos para as pesquisas é empresarial" (1996, 165). Se o mercado financia as pesquisas, ele determina temas, critérios, objetivos, prazos, padrões, usos, etc. Façamos um parênteses para dizer que a criação dessa universidade de serviços e de resulta- 
FIORIN, José Luiz. Reflexões para o estabelecimento de uma política para as Humanidades.

dos não é um plano malévolo urdido por um grupo de tecnocratas que estão encastelados nos órgãos governamentais. Se assim fosse, seria relativamente fácil combater essa idéia. Ao contrário, faz ela parte da lógica do desenvolvimento capitalista. Uma característica do capitalismo contemporâneo é a diminuição da acumulação de capital enquanto produtor de valor, ou scja, a diminuição da esfera da produção. A isso corresponde um aumento do setor de serviços, o setor terciário da economia. É dentro da lógica do desenvolvimento do setor de serviços que se insere a universidade como prestadora de serviços de ensino e de pesquisa. No setor terciário, tudo é feito em função do consumidor (Chauí, 1996, 167).

É bem possível que estejamos aproximando-nos de novo da inessencialidade do professor de história e de literatura de $A$ lista de Shindler. Mas não seremos todos excluídos, desde que, evidentemente, adaptemo-nos ao papel que o mercado traçou para nós. Como estamos acostumados a falar em I ingüística, há uma versão forte e uma versão fraca da nossa função na universidade moderna. A forte, que é a concepção dos neooliberais radicais (perdoem-me por usar uma expressão do "nhém-nhém-nhém" dos "saudosistas" c "ignorantes") é a de professores de línguas. Essa é a exigência do mercado universitário. Precisamos preparar os alunos das diversas faculdades para ler e escrever bem em português e em línguas estrangeiras, principalmente em inglês. 'Toda a reflexão sobre a produção literária, sobre os mecanismos c o funcionamento da linguagem e das línguas se torna inessencial. O que presidirá a área será a razão prática c não a razão teórica. Não é outro o motivo que tem levado prestigiosas universidades norte-americanas a fechar seus Departamentos de lingüística, por exemplo. Nesse sentido, perderemos o papel que sempre nos dignificou e deixaremos de ser aquilo que reputamos hoje essencial para ser considerados pesquisadores da área.

Há, por outro lado, uma versão fraca do nosso papel, exposta pelos neoliberais, que têm preocupações, digamos, sociais, aqueles que se preocupam com a desagregação produzida pela novas formas de acumulação. Para expor essa concepção, permito-me ler um trecho de um dos docu- 
Revisla da ANPOLL, $\mathrm{n}^{\prime \prime}$ 4, p. 301-321, jan./jun. 1998

mentos de trabalho preparados para o Seminário Nacional de Pós-graduação, promovido pela CAPES em dezembro de 1996. Nele, os autores, depois de discutir a questão da formação de pessoal pós-graduado e da pesquisa no Brasil, à luz do desenvolvimento econômico, principalmente do setor industrial, numa parte que tem o pomposo título de "visões de futuro", dizem:

\begin{abstract}
Outra característica dominante da civilização emergente é a redução do tempo de trabalho, e a maior disponibilidade para outras atividades. Dentre clas, e mesmo porque o que se vem construindo é um mundo calcado no conhecimento, a divulgação das descobertas científicas de uma maneira acessível ao leigo, o estímulo a atividades culturais e humanísticas, a participação nas artes serão pólos de atração para um crescente número de pessoas. O mundo anda fascinado pelo poder da ciência e da tecnologia, ao mesmo tempo que percebe que as conquistas materiais não são suficientes para satisfazer o ser humano $\mathrm{em}$ toda a sua plenitude. A grande expansão do gnosticismo está aí para testemunhar este fato. Portanto, existe um enorme vácuo que precisa ser preenchido pelo saber desvinculado de aplicações, pelas letras e pelas artes, pelas coisas do espírito, pela filosofia, pela teologia, pela religiāo, na retomada da incansável busca pelo sentido da vida c pelo transcendente. Certamente, continuarão os avanços nas áreas da tecnologia e particularmente nas áreas das ciências da vida, tanto básica como aplicada. Continuaremos na tentativa de desvendar os segredos do Universo e a procurar romper as fronteiras que nos confinam ao planeta Terra c ao sistema solar, mas veremos também um renascimento do alimento mais nobre do espírito humano, ciência, arte c religião (Bevilacqua et alii, 1996, 137).
\end{abstract}

É evidente que fazemos parte dos domínios do conhecimento que se preocupam com o sentido das coisas. Voltaremos a esse ponto mais adiante. No entanto, ao misturar letras, artes, teologia, filosofia, religião como meio de busca do transcendente, vejo que o mercado nos reserva o papel de domesticadores do homem submetido à brutal acumulação de capital que se processa. Certamente, caber-nos-á consolar os homens que sofrem a miséria material e a degradação da qualidade de vida, acenando-lhes com a elevação do espírito, ou submetê-los ao processo civilizatório exigido pelas novas condições de produção. Outra versão ainda para a nossa função é a de que serviremos para preencher o ócio, a fim de que os homens não pratiquem atos indesejados. Outra ainda é que serviremos para 
FIORIN, José Luiz. Reflexões para o estabelecimento de uma política para as Humanidades.

dar uma ilustração mundana aos que tiverem uma formação científica c tecnológica, serviremos para dar um colorido ao mundo. Não estaremos muito longe da velha concepção que pedia, para as "mocinhas, bons modos, piano, francês e filologia". Nossa área será inessencial, porque da ordem do supérfluo, do ornamental, ou será essencial, desde que não seja autônoma em relação às necessidades de domesticação do espírito da nova ordem econômica.

Diante dessa situação de escasso prestígio social e de baixa rentabilidade econômica, nossa atitude tem sido defensiva e não afirmativa. $\mathrm{O}$ estado patêmico mais comum é o do desalento e a atitude mais freqüente é a do lamento, quando não é a nostalgia conservadora do passado. Lamentamos que não nos dão importância, que não compreendem o nosso valor, que o verdadeiro papel das Letras e da Lingüística não é levado em conta. O lamento é uma atitude pouco afirmativa, porque se lamenta o que não se fez, o que não ocorreu, o que não aconteceu. O lamento é voltado para o passado, é um sentimento de impotência. Só lamentam os que estão modalizados pelo não poder fazer. A nostalgia do passado é conservadora, porque embute o desejo de restauração daquilo que o processo social objetivo não trará mais. Outra atitude bastante freqüente é a luta pela sobrevivência individual, sem nenhuma consideração pelo contexto. Aqui vemos a concorrência mesquinha por uma bolsa, por um auxílio, uma pequena verba, sem se importar com o sentido do trabalho na área. Trata-se de lutar no varejo, de ocupar-se dos detalhes, da miudeza da concorrência acadêmica. E aí vale tudo: desprestigiar áreas que concorrem com a nossa na obtenção de verbas, desqualificar os que não pensam como nós, etc. Ora, se acreditamos mesmo no valor e no sentido do que fazemos, da área em que trabalhamos, é preciso parar de lamentar, é necessário abandonar a nostalgia do passado, é imperioso pensar, de maneira mais ampla, uma política para nossa área, o que nunca conseguimos fazcr. Para isso, é urgente abandonar um pouco o varejo, é imperativo deixar de ver apenas nosso curso, nosso grupo de pesquisa, nossa universi- 
Revista da ANPOIJL, n" 4, p. 301-321, jan./jun. 1998

dade, nosso caso particular e elevar os olhos para a área, para o setor das Humanidades, para a Instituição Universitária e tentar compreender o papel que devem ter hoje e não sonhar em restaurar o que tinham na Idade Média ou no século XIX. Nossa atitude não pode ser a perplexidade do professor de história e de literatura, que não compreendia que o mundo, em que esses domínios do conhecimento eram essenciais, tinha acabado. É preciso pensar uma nova essencialidade para as l_etras e a Lingüística, não a essencialidade ditada pelo mercado, mas uma essencialidade voltada para a sociedade considerada $\mathrm{cm}$ sua totalidade. É preciso mostrar que as Humanidades têm um papel a exercer na construção do mundo. Não podemos deixar de lembrar para todos os que sonham com o passado "que qualquer discussão com o nosso passado exige um ajuste de contas com um elemento bastante pesado, no caso das próprias Humanidades: o fato de que a cultura funcionou, durante muito tempo, como um sustentáculo para o privilégio. Isto é, o homem de cultura, o homem que freqüentava os clássicos tinha, graças a essa freqüientação, uma justificação ideológica bastante boa para seus privilégios econômicos, sociais, políticos, etc. Um dos elementos básicos dos novos questionamentos que surgiram nas ciências humanas e sociais, para não falar nas Ilumanidades, nas últimas décadas, é o ajuste de contas com esses privilégios. Não será, pois, para a manutenção da velha cultura ou dos privilégios que poderemos defender o papel das humanidades hoje. (...) Não se trata de adaptar velhos fins a novos meios, mas também e sobretudo, de ver quais podem ser os fins das humanidades e da cultura hoje" (Ribeiro, 1996, 22).

Por isso, o primciro princípio norteador de uma política para as Humanidades é a questão da democracia, "não apenas como regime político, mas também como um estilo de vida e enquanto valor" (Ribeiro, $1996,22)$.

O segundo princípio norteador é que as I lumanidades trabalham basicamente com o sentido. Pode-se dizer delas o que disse Cecrtz a pro- 
FIORIN, José I uiz. Reflexões para o estabelecimento de uma política para as I Iumanidades.

pósito da ciência antropológica: "não é uma ciência experimental cm busca de leis, mas uma ciência interpretativa, à procura de significados". Embora certos campos da Lingüística sc aproximem das ciências experimentais, principalmente da biologia, em busca de leis, no seu todo e mesmo nesses casos, as I_etras e a lingüística buscam elucidar os significados da linguagem. Nesse sentido, devem elas filiar-se decididamente aos demais campos da Humanidades, que buscam o sentido da ação, do conhecimento, etc. Cabe lembrar que isso poderia revitalizar o papel das Humanidades num mundo em que se cultiva a ação e não a reflexão sobre a ação. Cabe destacar, porém, que "não podemos pensar nas Humanidades como um espaço no qual se encontre um sentido dado: o problema delas, mas também sua grande qualidade, reside no encontro do homem com o nãosentido e a decorrente construção dos sentidos, porém, apenas humanos, por isso, frágeis, superáveis, contestáveis. Esta talvez seja a grande contribuição, hoje, das Humanidades, na medida em que o que elas nos dizem, em última análise, é que a construção do homem é obra do próprio homem. Esta fragilidade é a dimensão de nossa liberdade" (Ribeiro, 1996, 23). Assim, é preciso ressemantizar a vida acadêmica, transformando o agir em fazer, os signos cm gestos. Essa ressemantização far-se-á do lugar cnunciativo de um país periférico, pois não nos iludamos, a globalização não nos transformou em país do primeiro mundo. A periferia do capitalismo é antes "um lugar de enunciação" do que "um espaço geográfico" (Pizarro, 1996, 52). Somos intrinsecamente leitores e nossa tarefa de leitores é perguntar pelos efeitos de sentido das categorias lingüísticas, pela significação dos seres ficcionais e de suas paixões de papel, etc. Cabe ainda explicar como se constroem esses efeitos de sentido, essas significações.

Uma política para as Humanidades deve estabelecer prioridades de pesquisa bascadas nos princípios norteadores esboçados acima. Tenho reiterado que nossa área possui muito pouca visibilidade. Conto sempre, porque me chocou, que um ex-presidente da SBPC, convidado a uma reunião da ANPOIL, que se realizou em Florianópolis, disse que se sentia 
Revista da ANPOLL, n" 4, p. 301-321, jan./jun. 1998

feliz por estar entre os guardiães do alfabeto. Nem sequer somos guardiães da língua! Uma política das Humanidades deve privilegiar resolutamente os projetos de grande alcance, que levem à produção de materiais indispensáveis para o conhecimento da língua e da literatura nacionais, das outras literaturas vernáculas e das línguas e das literaturas clássicas e modernas ou que conduzam à compreensão dos sentidos produzidos lingüisticamente. Temos ficado muito presos aos trabalhos individuais, muitas vezes relevantes, mas, em muitos casos, sem relevo maior. É o momento dos projetos de fôlego maior, que mostrem a indiscutível essencialidade da área. Esses projetos de maior alcance, de um lado, têm um cunho democrático, porque servem a uma parcela significativa da população; de outro, voltam-se para aquilo que constitui a especificidade das Humanidades, o trabalho com o sentido. É preciso ainda alertar que, quando falo de projetos de maior alcance, não estou pensando nesta contrafacção dos projetos temáticos, que é a soma de trabalhos individuais sobre o mesmo tema, muitas vezes até fundados em perspectivas teóricas divergentes.

O segundo ponto presente numa política das Humanidades é a acoIhida a novos temas, novos campos de pesquisa, novas abordagens de velhos problemas (penso aqui nas novas possibilidades da Lingüística Histórica e do estudo das Línguas Clássicas). Mas atenção! Não se trata de um make it new. Devemos propor novos problemas, porque correspondem a novas realidades, a novas experiências, a novas demandas sociais que requerem compreensão e interpretação (Chauí, 1996, p. 169).

O terceiro ponto é um engajamento efetivo da área de Letras e Lingüística no ensino da população deste país. Lucien Goldmann, em texto de 1967, intitulado Possibilidades de ação cultural através dos massmedia, faz uma detida análise do papel dos meios de comunicação de massas (rádio, televisão, quadrinhos, etc.) na sociedade capitalista de seu tempo. Não partilha do pessimismo radical da escola de Frankfurt, mas também não poderia ser considerado um integrado no sentido que Eco 
FIORIN, José Luiz. Reflexões para o estabelecimento de uma política para as Itumanidades.

deu a esse termo. Correndo o risco de simplificar e empobrecer seu pensamento, por retirar algumas afirmações do contexto, pode-se dizer que a tese defendida por ele, nesse texto, é que o excesso de informações desorganiza a compreensão $(1972,26)$. Se isso era verdade na década de 60, muito mais verdadeiro o é nos anos 90, quando o acesso à informação atinge patamares inimagináveis. A leitura e a escrita são meios ainda insubstituíveis de organização da informação. Portanto, ensinar a ler e a escrever, a compreender o texto, predominantemente o literário, principalmente ao que se costuma chamar camadas menos favorecidas da população, é tarefa absolutamente necessária. Ora, a área de I_etras e Lingüística deve engajar-se nesse trabalho de delinear as linhas de uma melhoria no ensino de língua e literatura maternas e de línguas e literaturas clássicas e modernas.

Além desses elementos que dizem respeito ao sentido da pesquisa, uma política para as Itumanidades deve conter aspectos relacionados às condições institucionais. O primeiro deles diz respeito à relação com as agências de pesquisa. No que concerne a esse ponto, é preciso fazer respeitar a especificidade da pesquisa em Humanidades. No entanto, antes de começar a desenvolver um pouco esse ponto, gostaria de repudiar energicamente um discurso da diferença que encobre um discurso da deficiência. Não se trata, em hipótese alguma, de admitir o discurso que encobre falhas, mas de expor aquele que aponta para diferenças genuínas. Em primeiro lugar, há que recusar critérios de avaliação fundados nas ciências exatas ou biológicas. Isso não quer dizer que as Humanidades não podem ser submetidas aos critérios gerais de avaliação das agências financiadoras, nem que o padrão de qualidade deva ser menor: Vamos começar por especificar o que são exigências legítimas. Há uma questão, que tem sido muito discutida no CT'C da CAPES, de que cada área qualifique sua produção. Essa exigência é legítima, pois nem todos os trabalhos que fazemos têm o mesmo peso. Se até o momento nossas especificidades têm sido respeitadas, não resta dúvida de que a área de Física é sempre apre- 
sentada como modelar, pois nela o que vale são papers publicados $\mathrm{em}$ revistas de circulação internacional. A relevância extrema atribuída aos papers e aos congressos não faz parte da tradição da nossa área. Se formos ver o que de mais relevante se fez em nossa área, vamos ver que está sob a forma de livros (Cf. Ribeiro, 1996, 20-21). Isso não quer dizer que os papers e os congressos não tenham relevância em nossa área, mas que os critérios de relevância não são exatamente os mesmos em todas as áreas. É imperioso qualificar a pesquisa, é necessário estabelecer sistemas rigorosos de arbitragem em nossas revistas, mas é preciso estabelecer critérios de relevância próprios da área. As mudanças implantadas pelo CNPq no modo de distribuição de bolsas são um exemplo de que, muitas vezes, critérios de relevância de outras áreas são aplicados à nossa.

Ademais, os auxílios para pesquisa e as bolsas para pesquisador não podem funcionar como política para o rebaixamento de salários. A política tem sido, atualmente, a de manter os salários baixos e o pesquisador deve complementá-lo seja em serviços de consultoria, assessoria, etc., seja conseguindo bolsas e auxílios (Cf. Chauí, 1996, 170).

Outro ponto que se deve enfatizar numa política de Humanidades é a garantia de recursos para a infraestrutura de docência e de pesquisa: bibliotecas, laboratórios, etc. (Cf. Chauí, 1996, 170). As bibliotecas precisam estar atualizadas, é imperativo interligá-las por redes e por serviços de trocas de periódicos, livros, etc., é necessário dinamizar a utilização de novas tecnologias de acesso à informação.

Outro ponto significativo a que não se deu muita importância é a política de difusão dos resultados da pesquisa: política editorial de livros e periódicos (Cf. Chauí, 1996, 170). Seria preciso estabelecer uma linha de financiamento para que as editoras universitárias publicassem mais livros e periódicos. Em contrapartida, essas editoras deveriam profissionalizar-se, profissionalizando principalmente a distribuição. Por outro lado, ao invés de multiplicarem-se as revistas em cada instituição, em cada grupo de pesquisa, em cada departamento, seria importante criar revistas nacionais re- 
FIORIN, José I uiz. Reflexões para o estabelecimento de uma polílica para as Humanidades.

almente fortes, talvez em torno das Associações Nacionais. Essas revistas deveriam ter um rigorosíssimo sistema de arbitragem, uma periodicidade menor e um número maior de páginas, admitindo apenas artigos que não tivessem a extensão ridícula de duas ou três páginas. Os artigos a serem publicados nas revistas nacionais deveriam ser aqueles que resultassem efetivamente de um trabalho de pesquisa e de reflexão e não pequenos textos escritos para cumprir formalmente as exigências de publicação.

Finalmente, é necessário estabelecer prioridades claras para uma política de indução por parte das agências de fomento. O medo da perda de espaço não tem permitido estabelecer, com clareza, quais as áreas que, por ter um baixo número de pesquisadores, precisariam ser mais estimuladas, por exemplo, com estímulo ao doutorado integral no exterior; quais as orientações teóricas que não se têm desenvolvido no Brasil e precisariam ter pesquisadores formados no exterior. O resultado disso é que os pedidos para doutoramento no exterior são fruto, na maioria dos casos, de veleidades de pessoas que não seriam accitas na pós-graduação no país. Um outro caso: que política de indução se deve executar para apoiar os Cursos de Pósgraduação lato sensu? Aqui entramos na selva acadêmica. Esses cursos pululam pelo país sem qualquer avaliação. É preciso estabelecer parâmetros claros para financiá-los com recursos públicos. É necessário eliminar distorções quanto a sua natureza, à composição do corpo docente, à estrutura curricular, aos itens financiáveis. A CAPES tem gasto cerca de 3 mithões de reais com esses cursos, sem que se saiba se atingem sua finalidade ou não.

É necessário pensar ainda a questão da formação de novas pesquisadores numa política para as I lumanidades (Cf. sobre esse tema Franchi, 1996). (O primeiro ponto que se enuncia é por que discutimos tanto a relação entre ensino e pesquisa. Marilena Chaú nota, com argúcia, que "esse problema foi inventado com a escolarização da graduação, e mesmo da pós-graduação, ou seja, com a transformação do ensino num conjunto de técnicas de transmissão de informações e conhecimentos. Não permi- 
Revisla da ANPOLL, n" +, p. 301-321, jan./jun. 1998

tindo o surgimento de sujeitos de conhecimento, não propiciando o aparecimento de pesquisadores a partir do próprio ensino, não fazendo da docência o modo fundamental de trabalhar academicamente, evidentemente cria-se o problema da relação entre ensino e pesquisa" (1996, 169). A questão é, portanto, fazer do ensino o lugar da pesquisa, levando os alunos a tornarem-se sujeitos do conhecimento. Isso é fácil de falar e difícil de fazer. Diferentes problemas se apresentam aqui. A primeira questão é se a pós-graduação deve dar uma formação geral dentro da disciplina ou deve especializar numa determinada subárea, ou mesmo numa perspectiva teórica. No primeiro caso, corre-se o risco de termos trabalhos de grau excessivamente genéricos, que não se dedicam a questões que podem parecer menores, mas que têm um impacto decisivo sobre a problematização de determinadas teorias. No segundo caso, temos um excesso de especialização, que impossibilita ao pós-graduado falar sobre outros temas ou subáreas com um mínimo de proficiência, pois ele tem um conhecimento apenas do estado da arte do pequeno recorte a que se dedica. Nesse caso, podemos ter trabalhos de grau fragmentários, de aplicação, cuja relevância é pequena, quando não nula.

Há muitos modelos de cientificidade em nossa área, desde aqueles que admitem a unidade metodológica da ciência, aí incluídas as Humanidades, que se subordinariam à exigência de uma explicação nomológica, até aqueles que contrapõem claramente as ciências humanas às ciências da natureza, pensando nos fundamentos hermenêuticos daquelas; desde os que defendem que fenômenos sociais, como a linguagem e a cultura, se tentam compreender como ramos da biologia até os que defendem a singularidade de cada um dos fenômenos sociais, a radical especificidade de cada texto, etc. Aliás, evidentemente não embasada com as descobertas da ciência contemporânea, a questão das diferentes concepções e estilos de ciência não é nova na área. Façamos um parênteses para dizer que talvez só a Aritmética c a Gcometria possam reclamar tão longa tradição quanto os estudos lingüísticos e literários. Usamos até hoje uma metalinguagem 
FIORIN, José I uiz. Reflexões para o estabelecimento de uma polílica para as I lumanidades.

que data de milênios. A questão a que me referia é a querela dos anomalistas e dos analogistas entre os gramáticos latinos. Estes assentam suas explicações na associação por semelhança, o que leva ao estabelecimento de conjuntos e até de leis. Aqueles, por sua vez, prescindem até mesmo de uma soma, "negando a possibilidade de um conjunto por associação de elementos. A rigor não chegam à gramática, que se reduz para eles em seguir o uso (consuetudinem sequens), como dizia o anomalista Aulo Célio" (Mattoso Câmara, s.d., 8). Para eles a realidade é única, não podendo ser generalizada. Para mim, essa é uma das características das ciências humanas: as diferentes concepções de ciência. Com efeito, se as teorias representam pontos de vistas históricos e sociais sobre os fenômenos humanos, não pode haver pontos de vista unívocos. É evidente que as Ciências Humanas compartilham com todas as outras ciências, o compromisso com o real e, por conseguinte, com a possibilidade de verificação das conclusões do cientista. Se a diversidade de concepções de ciência é da natureza da área, deve ela ser respeitada. O processo de formação deve ser variado. No entanto, o processo não pode ser escolarizado, não pode perder o caráter formativo e adquirir um caráter informativo. Em primeiro lugar, os programas oferecidos aos alunos não podem ser inorgânicos. Muitas vezes, privilegia-se a freqüência a disciplinas voltadas para subáreas muito diversas, reproduzindo-se na pós-graduação a estrutura curricular da graduação no que tem ela de pior. Nessa dispersão de disciplinas, não se aprofunda nada. O resultado são dissertações e teses que têm uma parte muito grande dedicada a resenhas, que nada têm a ver com a análise de fatos que segue, em que se fazem críticas canhestras derivadas de má leitura dos autores, em que a chamada discussão teórica tem um nível muito grande de generalidade ou não passa de introdução ao pensamento de um autor: Ademais, prima essa parte teórica pelo ecletismo, o que denota o desconhecimento de um modelo que seja escolhido em função da aceitação de seus pressupostos teóricos e de sua adequação à questão que está propondo responder.

Aqui nos vemos diante da questão extremamente espinhosa, já apontada acima, da oposição entre especialização e generalismo. De um 
lado, é verdade que o volume de conhecimento produzido hoje exige uma especialização muito grande e, por isso, não pode ser um pesquisador que contribua para o desenvolvimento de um determinado campo do conhecimento quem tiver uma visão panorâmica e superficial dele. Trabalhos que se ocupam de questões gerais e programáticas dificilmente trazem uma contribuição significativa ao avanço do conhecimento (Franchi, 1996, 34-35). Por outro lado, é constrangedor assistir ao total desconhecimento dos especialistas, que, formados dentro daquilo que Marilena Chauí chamou a taylorização do trabalho científico, não têm a menor noção do que se faz em outras subáreas, em outras linhas teóricas, etc. É verdade que o desenvolvimento da ciência, exige o "estudo aprofundado de uma teoria determinada" e o "exercício contínuo de scus modos de investigação, avaliação, argumentação e apresentação de resultados. Mais diretamente: pela inserção efetiva do formando num grupo de pesquisa, em que o conhecimento da teoria e de suas práticas resulte de uma construção compartiIhada e dialógica, da crítica e da contradição, e de uma revisão contínua na própria prática do fazer e do refazer" (Franchi, 1996, 34). No entanto, é preciso olhar em volta, porque senão o fazer científico acaba não permitindo a dúvida em relação à teoria, mas apenas a dúvida no interior dela. Como conciliar exigências tão díspares? Vão aqui algumas sugestões: a) o programa de estudos estabelecidos para o aluno deve circunscrever-se a uma subárea, dado que não é possível abarcar todas, mas contemplar nela mais de uma perspectiva teórica; b) deve-se instituir a prática da orientação coletiva, em que o andamento do trabalho de todos é compartilhado, criticado, etc. (evidentemente, para isso o orientador precisa ter um projeto de pesquisa muito claro e delineado); c) nessas orientações coletivas, devem ser examinadas e confrontadas as diversas linhas teóricas existentes numa dada subárea; d) devem ser evitados os cursos de caráter propedêutico, em que se examina uma pitada de tal autor, uma pitada de outro e não se aprofunda nada. Em outras palavras, duas devem ser as orientações na formação dos pós-graduandos: 1. a pesquisa é uma prática coletiva, por- 
FIORIN, José Luiz. Reflexões para o estabelecimento de uma polílica para as / Humanidades.

tanto, a formação do pesquisador deve dar-se fundamentalmente nos grupos de pesquisa; 2. os programas têm que ter organicidade, não podem ser o ajuntamento em que cada um trabalha numa coisa completamente diferente, o que impossibilita qualquer diálogo. Os cursos hão de ter poucas áreas, poucas linhas de pesquisa bem definidas. Evidentemente, as áreas e as linhas serão definidas em função do número de pesquisadores.

Não me filio à corrente dos que pensam que as ciências humanas sofrem a mesma obsolescência do conhecimento que as ciências biológicas, por exemplo. Ao contrário, penso que o que caracteriza as ciências humanas é uma não obsolescência das teorias, dos temas, etc. Daí, a atualidade dos clássicos. Para um homem de Letras, é tão importante conhecer a Poética de Aristóteles, quanto o último artigo de Derrida. Se me permitem a ironia, talvez até mais aquela do que este. No entanto, é preciso inserir-se no debate contemporâneo das questões científicas. Se acreditamos que as questões $\mathrm{em}$ debates são sugeridas pelas condições objetivas do processo social, que é sempre plural e dialeticamente contraditório, é colocar-se fora do tempo a atitude de negar importância, relevância c interesse ao debate contemporâneo, de marginalizar-se dele. Muitas vezes, ou na maioria da vezes, essa atitude revela preconceitos incompatíveis com o perfil de um homem de ciência, desatualização bibliográfica, temor de lançar-se na aventura do conhecimento. Ėm todos esses casos, estados que não recomendam o pesquisador.

Uma outra questão que surge é a da interdisciplinaridade, hoje tão decantada. A interdisciplinaridade não surge na instância $a$ quo do processo de pesquisa, mas na ad quem. A interdisciplinaridade estabelece-se como exigência do trabalho disciplinar, quando se verifica que um problema deve ser tratado sob diferentes óticas e perspectivas. Assim, a interdisciplinaridade não significa a diluição das teorias, dos métodos e das técnicas dos diferentes campos do conhecimento num todo amorfo e eclético, mas exige um profundo conhecimento da disciplina e do tratamento da questão que está sendo proposta. A interdisciplinaridade não é 
Revista da ANPOLL, no 4, p. 301-321, jan./jun. 1998

dada como pré-condição, mas surge como exigência interna ao trabalho que está sendo realizado. Não se cria interdisciplinaridade por decreto, mas ela é construída no cotidiano do pesquisador.

Ao longo desta conferência o que fiz foi delinear um painel das questões, que já foram debatidas por muitos autores e que devem estar presentes numa política científica para as I lumanidades. Cada um desses aspectos precisaria ser aprofundado. São basicamente questões ligadas ao sentido da pesquisa nas Humanidades e a problemas relacionados às condições de docência e de pesquisa. Naquelas, pensa-se nos princípios norteadores da pesquisa em Humanidades, o da democracia e o do trabalho com o sentido, bem como nas direções dessa pesquisa, os projetos integrados de maior alcance, a acolhida dos novos temas e o engajamento na mudança do ensino de línguas e de literaturas. Nestas, é preciso pensar a relação da área com as agências de fomento (definição de critérios de relevância da produção específicos da área, estabelecimento de uma política de criação da infraestrutura de pesquisa e de docência e de uma política de divulgação dos resultados da pesquisa, instituição de políticas de indução) c a questão da formação do pesquisador (não escolarização dos programas de pós-graduação, formação em grupos de pesquisa, especialização sem fechamento, interdisciplinaridade não mecânica, organicidade dos programas, inserção nos debates contemporâneos). O problema sério é que o estabelecimento de uma política que leve em conta esses aspectos vai chocar-se sempre com as contradições da realidade: trabalho com o sentido, mas sem perder de vista que o estilo das Humanidades não é a interpretação descompromissada, que as I lumanidades, como toda ciência, têm preocupação com a generalização e com a verificação dos resultados (afinal, já diziam os medievais, Nominantur singularia, sed significantur universalia); acolhida de novos temas e inserção no debate contemporâneo, mas sem esquecer os clássicos; especialização, mas com uma perspectiva ampla que não nos torne especialistas ignorantes; interdisciplinaridade, mas sem diluição das disciplinas num ecletismo estéril; preocupação com pesquisa 
FIORIN, José Luiz. Reflexões para o estabelecimento de uma política para as I Iumanidades.

séria de fatos lingüísticos e literários, mas sem perder de vista pressupostos teóricos e metodológicos das diferentes disciplinas; conhecimento profundo de uma orientação teórica, mas sem ignorar o estado da arte do campo de estudos e, se possível, de outros campos do conhecimento. É indispensável estabelecer, em meio a esses conflitos e contradições, diretrizes para uma política da área, sem o que não passaremos nunca para uma ação afirmativa, quedando no lamento estéril e na nostalgia conservadora. É imperioso traçarmos diretrizes, estabelecermos uma política para a área. Os presidentes da agências federais de fomento têm insistido com os representantes de áreas e com membros de comitês assessores na necessidade dessas políticas para orientar as ações das agências. Nossa resposta não tem sido afirmativa, deixando nossos representantes sem uma direção clara de atuação. Estamos enredados nessa teia de dificuldades e adotamos uma atitude defensiva ou então optamos pela discussão do varejo. Acho que estamos na situação de Riobaldo, quando diz:

Baixei, mas fui ponteando opostos. Que isso foi o que sempre me invocou, o senhor sabe: eu careço de que o bom seja bom e o rúim rúim, que de um laro esteja o preto e do outro o branco, que o feio fique bem apartado do bonito e a alegria longe da tristeza! Quero os todos pastos demarcados... Como é que posso com este mundo? A vida é ingrata no macio de si, mas transtraz a esperança mesmo no meio do fel do desespero. Ao que, este mundo é muito misturado (Grande serlão: veredas. 3 ed. Rio, J. Olympio, 1963, p. 210).

Preferiríamos que, na situação atual de nossa área, os pastos fossem todos bem demarcados. No entanto, o mundo é muito misturado e é, enfrentando a mistura, o conflito, a divergência, a contradição, que temos que estabelecer prioridades e políticas. É preciso decididamente pôr o varejo de lado e passar a operar no atacado, aprofundando cada um dos pontos aqui esboçados. 
Revista da ANPOLL, n" 4, p. 301-321, jan./jun. 1998

\section{BIBLIOGRAFIA}

BEVILACQUA, Luiz et alii (1996) "Formação de pessoal pós-graduado e pesquisa no Brasil". In: Discussão da Pós-graduação brasileira. Brasília, MEC.

BRONDAL, V. (1986) Omnis et totus. Documents. Paris, CRSL-EIIESS-CNRS, VIII, 72, 1986.

CÂMARA.Jr., J. Mattoso (s.d.). O estruturalismo lingüístico. Rio de Janeiro, Tempo Brasileiro, 15/16.

CHAUÍ, Marilena (1996). "Perspectivas para o futuro". In: Ilumanidades, pesquisa, universidade. São Paulo, FFI,CH-USP, p. 159-161.

FRANCHI, Carlos (1996). "A formação do pesquisador na área de llumanidades na universidade brasileira”. In: Ilumanidades, pesquisa, universidade. São Paulo, FFICII-USP, p. 25-40.

GOLDMAN, Lucien (1972). A criação cultural na sociedade moderna. São Paulo, Difusão Européia do Livro.

PIZARRO, Ana (1996). "Notas sobre la investigación en Ilumanidades". In: Humanidades, pesquisa, universidade. São Paulo, FFLCIH-USP, p. 45-5.3.

RIBEIRO, Renato Janine (1996). "Comentários ao texto de Milton Santos". In: Ilumanidades, pesquisa, universidade. São Paulo, FFI_CII-USP, p. 18-23.

SILVA, Franklin Lcopoldo e (1996). "Universidade, I lumanidades e Filosofia". In: I lumanidades, pesquisa, universidade. São Paulo, FFLCII-USP, p. 105-117. 